\title{
Novel strategy of endoscopic submucosal dissection using an insulation-tipped knife for early gastric cancer: near-side approach method
}

Authors

Institution
Genki Mori, Satoru Nonaka, Ichiro Oda, Seiichiro Abe, Haruhisa Suzuki, Shigetaka Yoshinaga, Takeshi Nakajima, Yutaka Saito

Endoscopy Division, National Cancer Center Hospital, Tokyo, Japan submitted $\quad 8$. January 2015 accepted after revision 7. May 2015

\section{Bibliography}

Dol http://dx.doi.org/ 10.1055/s-0034-1392567 Published online: 2.9.2015 Endoscopy International Open 2015; 03: E425-E431

(c) Georg Thieme Verlag KG Stuttgart . New York E-ISSN 2196-9736

\section{Corresponding author}

\section{Satoru Nonaka, MD}

Endoscopy Division

National Cancer Center Hospital 5-1-1 Tsukiji

Chuo-ku

Tokyo 104-0045

Japan

Fax: +81-3-35423815

snonaka@ncc.go.jp
Background and study aims: Endoscopic submucosal dissection (ESD) using insulation-tipped knives (IT knives) to treat gastric lesions located on the greater curvature of the gastric body remains technically challenging because of the associated bleeding, control of which can be difficult and time consuming. To eliminate these difficulties, we developed a novel strategy which we have called the "near-side approach method" and assessed its utility.

Patients and methods: We reviewed patients who underwent ESD for solitary early gastric cancer located on the greater curvature of the gastric body from January 2003 to September 2014. The technical results of ESD were compared between the group treated with the novel near-side approach method and the group treated with the conventional method.

Results: This study included 238 patients with 238 lesions, 118 of which were removed using

\section{Introduction}

\section{$\nabla$}

Endoscopic submucosal dissection (ESD) has become an effective, minimally invasive local treatment for early stage gastric cancer with a negligible risk of lymph node metastasis [1 -4], and with favorable long-term outcomes [5-12]. Recent advances in endoscopic technology and instruments have made gastric ESD technically more feasible [13-19]. Some lesions, such as those located on the greater curvature of the gastric body, however, remain technically challenging due to the pooling of water and blood as a result of gravity, difficulty in handling the endoscope in the retroflex view, and the high frequency of thick vessels in the submucosal layer with bleeding easily started. Identifying the source of bleeding can be difficult.

High-frequency knives used in gastric ESD are broadly classified as either insulation-tipped knives (IT knives) or needle-type knives. The IT knife the near-side approach method and 120 of which were removed using the conventional method. The median procedure time was 92 minutes for the near-side approach method and 120 minutes for the conventional method. The procedure time was significantly shorter in the near-side approach method arm. Although, the procedure time required by an experienced endoscopist was not significantly different between the two groups (100 vs. 110 minutes), the near-side approach group showed significantly shorter procedure time for a less-experienced endoscopist (90 vs. 120 minutes).

Conclusions: The near-side approach method appears to require less time to complete gastric ESD than the conventional method using IT knives for technically challenging lesions located on the greater curvature of the gastric body, especially if the procedure is performed by less-experienced endoscopists.

was developed by Ono et al. at the National Cancer Center Hospital in the late 1990s and has been used during ESD since the initial development of the procedure [2] ( $\bullet$ Fig. 1). The needletype knives were developed around the same time $[13,14]$ ( Fig.2). Because of the technical differences between these two types of knife, different approaches are used in gastric ESD. Tissue is incised and dissected by pulling the IT knife, but by pushing with the needle-type knife. Using a needle-type knife, the endoscopist begins mucosal incision and submucosal dissection at the near side of the field of view and proceeds toward the far side. In contrast, when using an IT knife, the endoscopist begins by making the initial incision at the far side of the field of view, makes mucosal incisions from the far to the near side, and then, following a circular incision, proceeds to perform the submucosal dissection ( $\bullet$ Fig.3). This strategy has been established and spread widely as the standard method of gastric ESD 

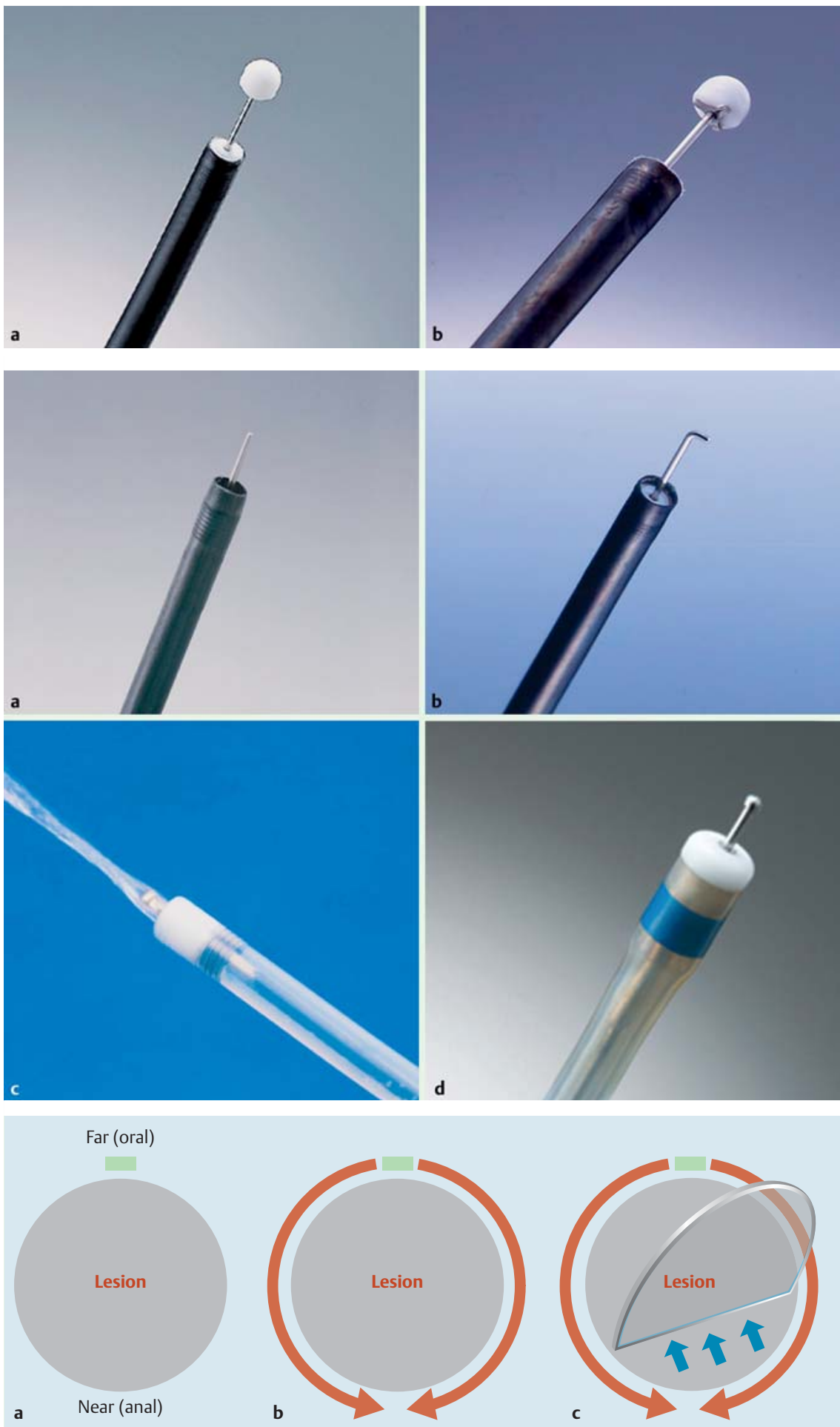

Fig. 1 IT knives. a IT knife (Olympus Medical Systems Co., Ltd, Tokyo, Japan). b IT knife-2 (Olympus).

Fig. 2 Needle type knives. a Needle knife (Olympus). b Hook knife (Olympus). c Flash knife BT (Fujifilm, Tokyo, Japan). d Dual knife (Olympus).

Fig. 3 Conventional method using IT knife. a An initial incision is made with Needle knife on the far (oral) side of the field of retroflex view. b A circumferential mucosal incision is performed with IT knife/IT knife-2 from the far (oral) to the near (anal) side. c Submucosal dissection is performed with IT knife/IT knife-2. using the IT knife (conventional method). Gastric ESD can be performed successfully in most areas of the stomach with the conventional method using the IT knife at our institution. However, when dissecting lesions on the greater curvature of the gastric body, the control of bleeding is often difficult and time consuming, especially during mucosal incision. Using the IT knife and pulling from the far to the near side makes the field of work blind in the case of bleeding. Thus, it is difficult to see precisely the bleeding points without enlarging the masked incision which may cause new bleeding ( $\bullet$ Video 1 ).
To eliminate these difficulties, we recently developed a novel strategy, the near-side approach method, which adopts components of the needle-type knife technique into the conventional IT knife approach. The near-side approach applies a step by step incision from the near side to open the incision space quickly and makes bleeding control easier ( $\bullet$ Video 2 ).

We conducted a study to examine the utility of the near-side approach method for removing lesions located on the greater curvature of the gastric body and compared it with the conventional method. 


\section{Patients and methods}

$\nabla$

We retrospectively analyzed consecutive patients who underwent ESD for solitary early gastric cancer located on the greater curvature in the upper or middle third of the stomach from January 2003 to September 2014 at the National Cancer Center Hospital in Tokyo, Japan. A lesion was defined as a greater curvature lesion when at least one-third of the area resected was at the greater curvature. All ESD procedures for lesions located on the greater curvature of the upper to middle gastric body surely must be performed in retroflex view. Therefore, lesions on the greater curvature at the angular region in the middle third of the stomach, which are mainly resected in forward view, were excluded from this study. Patients with gastric cancer in the remnant stomach and the reconstructed gastric tube after surgery as well as patients with locally recurrent gastric cancer were also excluded from this study. Gastric cancer was universally diagnosed according to the Japanese Classification of Gastric Carcinoma [20]. All lesions were preoperatively determined as an absolute indication or expanded indication in the weekly multidisciplinary conference according to the Japanese Gastric Cancer Treatment Guidelines [21].

The main outcome measurements were patient characteristics, endoscopic findings, pathological findings, experiences of performing endoscopists, and technical results (i.e. procedure time, en bloc resection, $\mathrm{R} 0$ resection, and perforation). The institutional review board of the hospital approved the study, and informed consent was obtained from all patients in accordance with the institutional protocol.

\section{ESD procedure}

ESD was performed using a video scope system (EVIS LUCERA or EVIS LUCERA ELITE; Olympus Medical Systems Co., Ltd, Tokyo, Japan) and standard forward-viewing endoscopes (GIF-Q240, Q260, 1T240, Q260J, 2TQ260M; Olympus). All gastric ESD procedures were basically performed using an IT knife/IT knife-2 (Olympus) apart from the initial incision by needle-type knife (Needle knife or Dual knife; Olympus). An IT knife was used until October 2007, and an IT knife-2 was used from November 2007. The ICC200 and VIO300D (ERBE, Tübingen, Germany), and
ESG100 (Olympus) were used as the electrosurgical generator. A transparent attachment was fitted at the tip of the endoscope. All patients were admitted for ESD which was conducted under intravenous anesthesia without tracheal intubation in the dedicated endoscopy suite.

At the start of the procedure, an initial marking was made around the lesion. Saline with indigo carmine and epinephrine, or a mixture of saline and sodium hyaluronate (MucoUp; Johnson \& Johnson Co., Ltd, Tokyo, Japan), was locally injected into the submucosa. ESD procedures for lesions located on the greater curvature of the gastric body must be performed in retroflex view. Therefore, the oral side of the lesion corresponds to the far side of the field of view, and the anal side corresponds to the near side. The procedures for making an initial incision and a mucosal incision differ between the conventional and near-side approach methods. In the conventional method, an initial incision is made on the far side of the field of retroflex view ( $\bullet$ Fig. 3 a), mucosal incision is performed with an IT knife/IT knife-2 from the far to the near side ( $\bullet$ Fig. 3b), and a circular incision is made to accomplish submucosal dissection ( Fig.3c). In the near-side approach method, initial incisions are made on the lateral side of the lesion and a mucosal incision is made with an IT knife/IT knife-2 for about one-third or one-half of the circumference on the near side of the field of view ( Fig.4a-1). Alternatively, a Dual knife is used to make a mucosal incision on the near side of the field of view ( Fig.4a-2). Then, submucosal dissection with an IT knife/IT knife-2 is begun on the near side ( $\bullet$ Fig. $\mathbf{4 b}$ ), the circular mucosal incision is completed, and the remaining submucosal dissection is performed ( Fig.4c). Any bleeding is managed using forced coagulation with ESD knives or soft coagulation with hemostatic forceps (Hot biopsy; Boston Scientific Co., Ltd, Tokyo, Japan, Coagrasper; Olympus). The near-side approach method has been gradually introduced from 2007 ( $\bullet$ Fig.5). The ESD procedure time was defined as the time from the beginning of marking to lesion removal.

ESD was performed by experienced endoscopists or less-experienced endoscopists under the guidance of an experienced endoscopist. An experienced endoscopist was defined as someone who had performed at least 100 gastric ESD procedures, and a less-experienced endoscopist as someone who had performed fewer

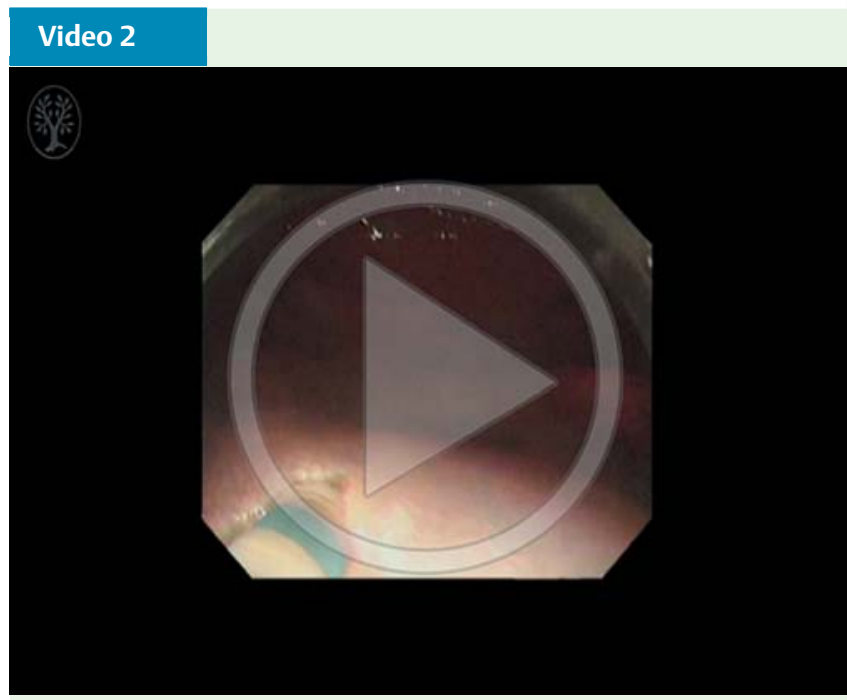

Near-side approach method. Online content including video sequences viewable at: http://dx.doi.org/10.1055/s-0034-1392567
Conventional method using IT knife. Online content including video sequences viewable at: http://dx.doi.org/10.1055/s-0034-1392567

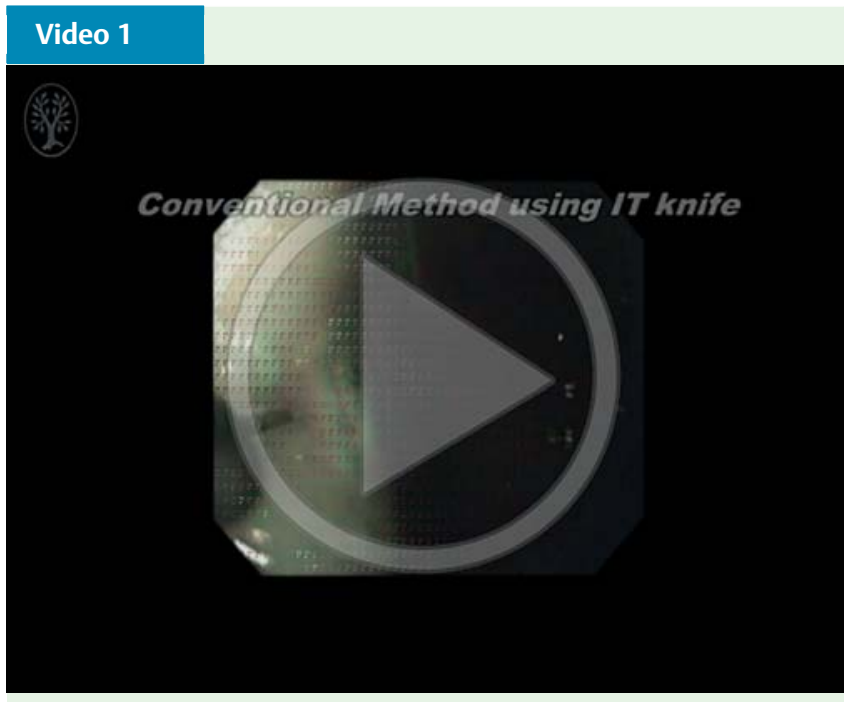

(1) 


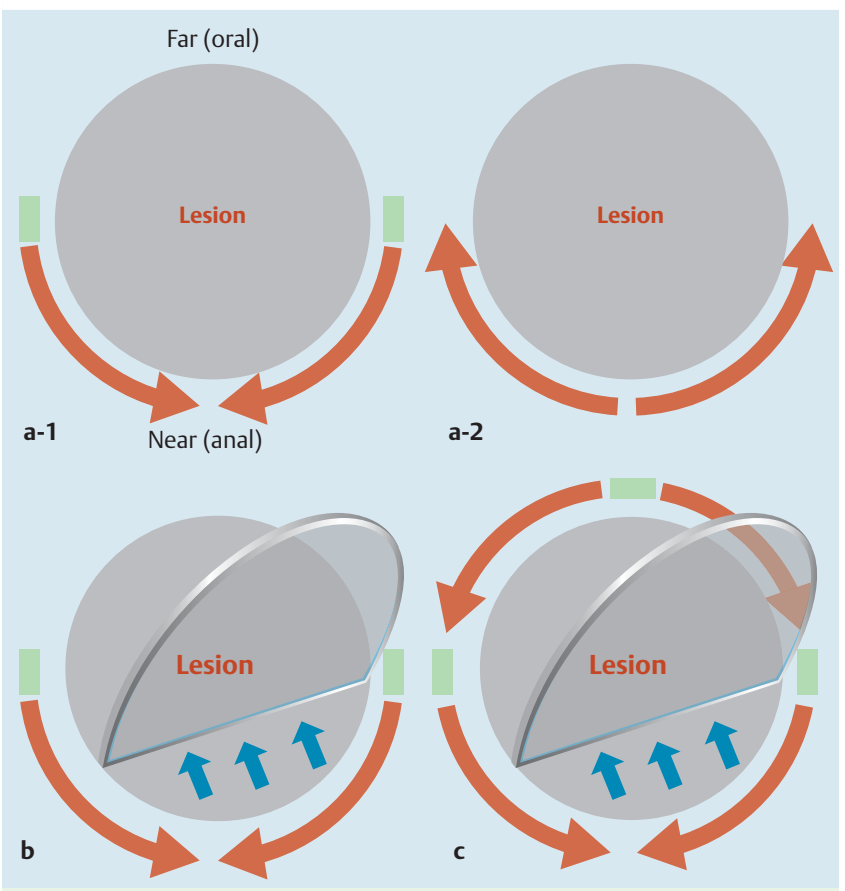

Fig. 4 Near-side approach method. a-1 Initial incisions are made with Needle knife on the lateral sides of the lesion and a mucosal incision is made with IT knife/IT knife-2 for about one-third or one-half of the circumference on the near (anal) side of the field of view. a-2 Alternatively, a mucosa incision is made with Dual knife for about one-third or one-half of the circumference on the near (anal) side. $\mathbf{b}$ Submucosal dissection is performed with IT knife/IT knife-2 on the near (anal) side. c A circumferential mucosal incision is completed and the submucosal dissection is performed with IT knife/IT knife-2.

than 100 procedures. When the operator reached 100 gastric ESD procedures during the study period, they subsequently changed their group from "less-experienced" to "experienced". Each operator was allowed to choose either the near-side approach or conventional method based on their preference. It could be confirmed whether the near-side approach method was applied or not, based on reviewing the endoscopic images taken during the ESD procedures.

\section{Histopathological assessments}

ESD specimens were carefully evaluated in slices at 2-mm intervals by gastrointestinal tract pathologists according to the Japanese Classification of Gastric Carcinoma [20]. An R0 resection was defined as complete removal of the cancer, with the margins of the removed area being histologically negative. Depth, lymphovascular invasion, and histological type of tumor were not considered.

\section{Statistical analysis}

All variables in this study were described in terms of mean, standard deviation, median, and range. Student's $t$ test, chisquared test, and Mann-Whitney $U$ test were used for statistical analyses of near-side approach and conventional method groups, with $P<0.05$ constituting a statistically significant difference. All statistical analyses were performed using statistical analysis software (SPSS, version 20; SPSS Japan Inc, Tokyo, Japan).

\section{Results \\ $\nabla$}

\section{Patient characteristics and endoscopic findings}

This study included 238 patients with 238 lesions, 118 of which were removed by ESD using the near-side approach method and 120 using the conventional method. No statistically significant differences in patient characteristics and endoscopic findings were noted between the groups ( $\bullet$ Table 1 ).

\section{Endoscopists}

This study included a total of 47 endoscopists. Among them, 10 were experienced and 42 were less-experienced. Among the less-experienced endoscopists, five performed less than 30 gastric ESD procedures and 37 performed 30-99 procedures. Five endoscopists overlapped both groups because they experienced 100 gastric ESD procedures during the study period and their group changed from "less-experienced" to "experienced". - Table 2 shows 11 endoscopists with their methods who performed more than five ESD procedures in this study.

\section{Technical results}

The experienced endoscopists performed 74 (63\%) of the procedures in the near-side group and 61 (51\%) in the conventional group. The median procedure time was 92 minutes (range, $30-$ 270 minutes) for the near-side approach and 120 minutes (20-

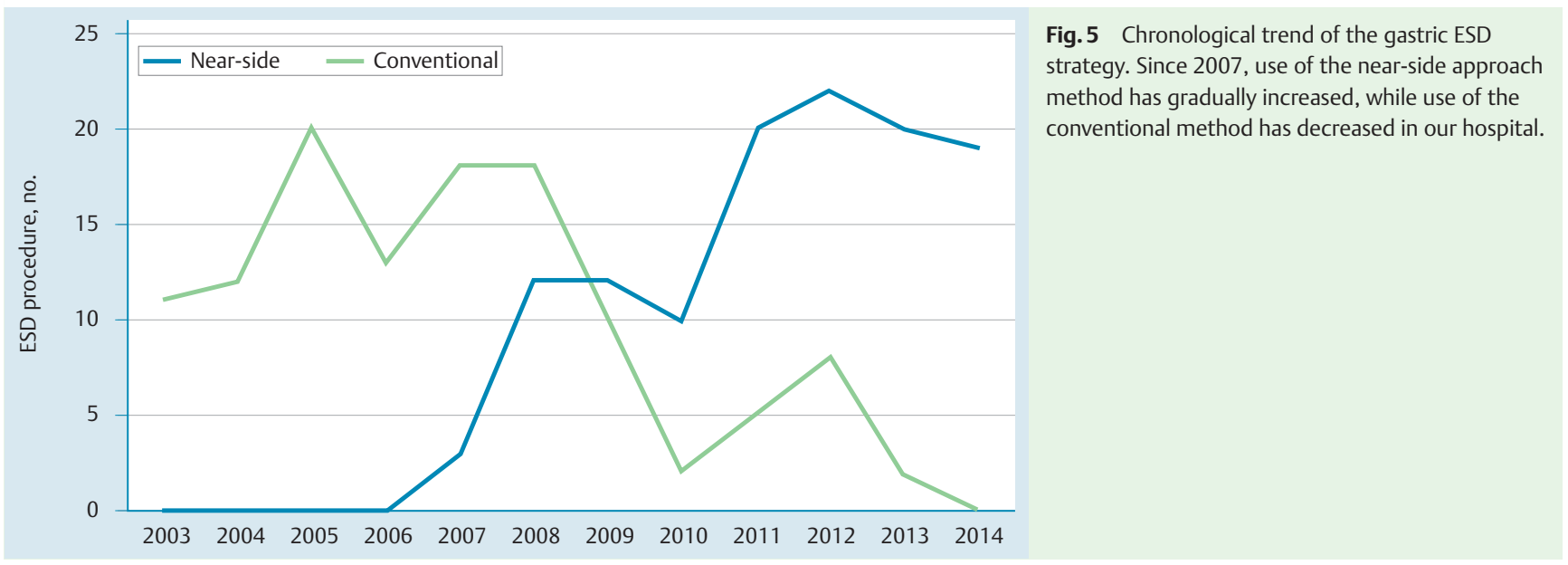


Table 1 Clinicopathological characteristics of both groups.

\begin{tabular}{|c|c|c|c|}
\hline & Near-side & Conventional & $P$ value \\
\hline Lesions, $\mathrm{n}$ & 118 & 120 & \\
\hline Age, mean $( \pm S D)$, years & $67.8( \pm 9.4)$ & $67.5( \pm 9.7)$ & 0.81 \\
\hline Male/female & $100 / 18$ & $101 / 19$ & 0.90 \\
\hline Location, n (\%) & & & 0.14 \\
\hline Upper third & $47(40)$ & $37(31)$ & \\
\hline Middle third & $71(60)$ & $83(69)$ & \\
\hline Macroscopic type, n (\%) & & & 0.76 \\
\hline $0-1$ & $6(5)$ & $3(3)$ & \\
\hline 0 - Ila & $36(31)$ & $42(35)$ & \\
\hline $0-11 \mathrm{c}$ & $69(58)$ & $62(51)$ & \\
\hline $0-\|l a+\| c$ & $7(6)$ & $13(11)$ & \\
\hline Tumor size, median (range), mm & $17(2-65)$ & $18(2-105)$ & 0.52 \\
\hline Ulceration, n (\%) & & & 0.37 \\
\hline Present & $21(18)$ & $27(23)$ & \\
\hline Absent & $97(82)$ & $93(77)$ & \\
\hline Biopsy, n (\%) & & & 0.34 \\
\hline Differentiated type & $111(94)$ & $116(97)$ & \\
\hline Undifferentiated type & $7(6)$ & $4(3)$ & \\
\hline Clinical indication, $\mathrm{n}(\%)$ & & & 0.30 \\
\hline Absolute & $56(47)$ & $49(41)$ & \\
\hline Expanded & $62(53)$ & $71(59)$ & \\
\hline
\end{tabular}

540 minutes) for the conventional method ( $\triangle$ Table 3 ). The procedure time was significantly shorter in the near-side group $(P=$ 0.01 ). The experienced endoscopists required 100 minutes (30270) for the near-side approach and 110 minutes (20-540) for the conventional method, and the procedure time was not significantly different between the two groups.

The less-experienced endoscopists performed 44 (37\%) of the procedures in the near-side group and 59 (49\%) in the conventional group, requiring 90 minutes (40-240) and 120 minutes $(30-510)$, respectively. The procedure time was significantly shorter in the near-side group $(P=0.01)$ when performed by the less-experienced endoscopists.

As for the distribution of the procedure times, $>3$ hours and $>4$ hours was necessary for ESD in $16 \%(19 / 118)$ and $3 \%(4 / 118)$ of the patients in the near-side group, and 28\% (33/120) and $13 \%$ $(16 / 120)$ of the patients in the conventional group, respectively ( Fig. 6). The proportions of procedure of $>3$ hours and $>4$ hours were significantly lower in the near-side group compared with the conventional group ( $P=0.03$ and 0.01 , respectively). The median size of the resected specimens in the near-side and conventional groups was $42 \mathrm{~mm}(20-96)$ and $42 \mathrm{~mm}$ (20-110), respec-
Table 2 Number of cases with each method by 11 endoscopists who performed more than five ESD procedures in this study.

\begin{tabular}{|l|cccl|}
\hline Endoscopist & Near-side & Conventional & Total & Period \\
\hline A & 26 & 19 & 45 & $2003-2014$ \\
\hline B & 19 & 2 & 21 & $2008-2014$ \\
\hline C & 19 & 1 & 20 & $2009-2014$ \\
\hline D & 0 & 17 & 17 & $2003-2009$ \\
\hline E & 10 & 7 & 17 & $2006-2014$ \\
\hline F & 3 & 12 & 15 & $2007-2013$ \\
\hline G & 10 & 0 & 10 & $2011-2014$ \\
\hline H & 0 & 8 & 8 & $2004-2008$ \\
\hline I & 7 & 0 & 7 & $2013-2014$ \\
\hline J & 0 & 6 & 6 & 2009 \\
\hline K & 1 & 4 & 5 & $2008-2012$ \\
\hline Total & 95 & 76 & 171 & $2003-2014$ \\
\hline
\end{tabular}

tively ( Table 3 ). En bloc resection was achieved in $100 \%$ of patients in both groups, and the proportions of R0 resections were $97 \%$ and $96 \%$, in near-side and conventional groups, respectively. The multi-bending scope was used in 15\% (18/118) of the nearside approach group and $10 \%(12 / 120)$ of the conventional group.Perforation occurred in $4 \%$ of the near-side approach group and $7 \%$ of the conventional group.

\section{Discussion}

This study examined the near-side approach method for gastric ESD using IT knives, a new strategy for technically challenging lesions located on the greater curvature of the gastric body, which could shorten the procedure time, particularly when gastric ESD is performed by less experienced endoscopists.

Factors influencing the length of gastric ESD include lesion location in the upper third, large tumor size, and the presence of ulcer scars [7,22 - 24]. The extreme technical difficulty of performing ESD on lesions located on the greater curvature of the gastric body, although not documented in the literature, is empirically known. In our study, median ESD procedure time for lesions on the greater curvature of the gastric body using the conventional method was long, at 120 minutes, and $28 \%$ of procedures took 3 hours or more to complete ( Table 3). Long ESD procedures pose a risk of postoperative pneumonia [25] and can adversely affect patient condition. Consequently, technical developments aiming to reduce procedure time are necessary, and effective control of bleeding during gastric ESD is probably the best way to shorten

\begin{tabular}{|c|c|c|c|c|}
\hline & Near-side $(n=118)$ & Conventional $(n=120)$ & $P$ value & \multirow{14}{*}{$\begin{array}{l}\text { Table } 3 \text { Technical results for } \\
\text { both groups. }\end{array}$} \\
\hline Operator, n (\%) & & & 0.18 & \\
\hline Experienced endoscopists & $74(63)$ & $61(51)$ & & \\
\hline Less-experienced endoscopists & $44(37)$ & $59(49)$ & & \\
\hline Procedure time, median(range), min & $92(30-270)$ & $120(20-540)$ & 0.01 & \\
\hline Experienced endoscopists & $100(30-270)$ & $110(20-540)$ & 0.36 & \\
\hline Less-experienced endoscopists & $90(40-240)$ & $120(30-510)$ & 0.01 & \\
\hline$>3$ hours, $n(\%)$ & $19(16)$ & $33(28)$ & 0.03 & \\
\hline$>4$ hours, $n(\%)$ & $4(3)$ & $16(13)$ & 0.01 & \\
\hline Resected specimen size, median (range), mm & $42(20-96)$ & $42(20-110)$ & 0.67 & \\
\hline \multicolumn{4}{|l|}{ Results of resection, $\mathrm{n}(\%)$} & \\
\hline En bloc & $118(100)$ & $120(100)$ & & \\
\hline RO & $114(97)$ & $115(96)$ & 0.76 & \\
\hline Perforation, $\mathrm{n}(\%)$ & $5(4)$ & $8(7)$ & 0.41 & \\
\hline
\end{tabular}




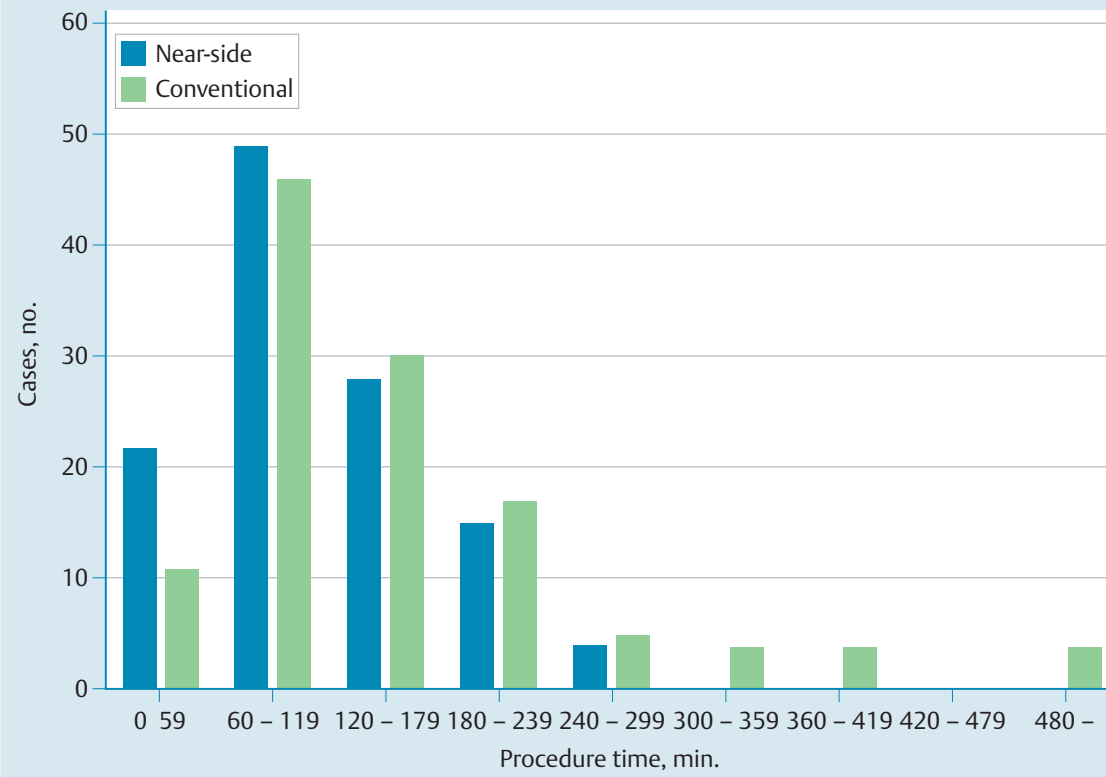

Fig. 6 Procedure time of ESD in both groups. The procedure time was significantly shorter and proportions of ESD over 3 or 4 hours were lower in the near-side group.

the procedure time of gastric ESD, which is essentially a fight against bleeding and often more time is required for hemostasis than for tissue removal itself [26]. The many submucosal arteries with large diameter present in the upper and middle thirds of the stomach, in comparison to the lower third, cause frequent intraoperative hemorrhage [27]. Bleeding sites in the greater curvature of the gastric body are soon inundated with fluids due to gravity and the resulting poor visibility further complicates hemostasis. Attempts to blindly stop bleeding often not only fail, but also result in unnecessary burning of surrounding tissue, which hampers subsequent ESD procedures. Control of bleeding is, thus, critical for successful ESD performed in the stomach, particularly on the greater curvature of the gastric body.

With the conventional method, an initial incision is made on the far side of the field of view, followed by a mucosal incision from the far to the near side using IT knives ( Fig. 3). Areas of bleeding are covered by the near side region, which has not yet been incised or dissected, and which complicates hemostasis because of poor visibility of the point of bleeding ( Video 1 ). However, with the near-side approach method, incision and dissection proceed from the near side of the field of view, which improves visualization of any sites of bleeding and simplifies hemostasis ( $\bullet$ Fig. 4; $\triangle$ Video 2). Using the near-side approach method, a smaller proportion of ESD procedures required 3 or 4 hours to complete compared to the conventional method, possibly because the operator was able to proceed with efficient removal of the lesion by virtue of better hemostasis.

IT knives and needle-type knives have opposite characteristics to each other; IT knives are safe and fast, but require proper handling of the endoscope, while needle-type knives offer higher resectability, but a higher risk of perforations, and resection is slow. Furthermore, the original IT knife had been developed in our hospital and we have developed the technique of ESD using IT knives. The near-side approach method combines IT knife and needle-type knife strategies to reduce the risk of making the point of bleeding difficult to recognize, and does not impair the advantages of the IT knife as a safe and fast method. In the nearside approach method, most of the gastric ESD procedure was performed using the IT knife; the needle knife was mainly used for the initial incision ( $\bullet$ Fig.4a-1), and the Dual knife was main- ly used for the initial and half-circumferential mucosal incision ( $\bullet$ Fig.4a-2). On the other hand, in the conventional method, the Needle knife was basically only used for the initial incision. Operators who are familiar with IT knives will find the near-side approach method easy to implement because of no requirements for special devices or technologies.

We classified the endoscopists as experienced or less-experienced according to the number of gastric ESD procedures performed because operator skill can affect procedure time ( $\bullet$ Table 3). The procedure times required by the experienced endoscopists for the completion of near-side approach and conventional methods did not differ statistically (100 vs. 110 minutes). This difference in procedure time was attributed to the small variation in time required for hemostasis in the two methods so that the experienced endoscopists could control bleeding effectively. The procedure time for the less-experienced endoscopists, however, was significantly shorter with the near-side approach method (90 vs. 120 minutes). Being less skilled in the hemostasis technique, the less-experienced endoscopists appeared to require more time to stop bleeding when using the conventional method in which there is often a reduced visibility of the bleeding sites. Consequently, the near-side approach method is recommended for ESD of lesions on the greater curvature of the gastric body performed by less-experienced endoscopists. Although the procedure time will not likely differ based on our results when experienced endoscopists conduct the gastric ESD procedure under both strategies, we believe the near-side approach method can also be recommended for experienced endoscopists to avoid difficult situations requiring bleeding control and to provide a high-quality procedure.

Our study has several limitations such as the single-center, retrospective design. Although analysis began with patients treated in 2003, the near-side approach method was gradually introduced from 2007, meaning that the periods during which the nearside approach and conventional methods were used did not coincide ( Fig.5). Development of equipment (multi-bending scope, sodium hyaluronate, and Dual knife, among others) and technical advances of the ESD procedure during the study period might have an influence on the results. Essential ESD equipment had already become available in 2003 [28], and the ESD technique 
using IT knives had also been established in our institution. As a result, this limitation would have little influence on the overall results.

In conclusion, for technically challenging lesions located on the greater curvature of the gastric body, our results indicate that the near-side approach method for gastric ESD using IT knives requires less time to complete than the conventional method, especially when performed by less-experienced endoscopists. This is because the near-side approach method improves access to points of bleeding and simplifies bleeding control.

\section{Competing interests: None}

\section{Acknowledgment}

\section{$\nabla$}

The authors express their appreciation to Dr Milan Bassan and Dr Metzner Magdalena for their assistance in editing this manuscript.

\section{References}

1 Gotoda T, Yanagisawa A, Sasako M et al. Incidence of lymph node metastasis from early gastric cancer: estimation with a large number of cases at two large centers. Gastric Cancer 2000; 3: 219-225

$2 \mathrm{Ono} H$, Kondo H, Gotoda T et al. Endoscopic mucosal resection for treatment of early gastric cancer. Gut 2001; 48: 225-229

3 Gotoda T, Yamamoto H, Soetikno R. Endoscopic submucosal dissection of early gastric cancer. J Gastroenterol 2006; 41: 929-942

4 Soetikno R, Kaltenbach $T$, Yeh $R$ et al. Endoscopic mucosal resection for early cancers of the upper gastrointestinal tract. J Clin Oncol 2005; 23: $4490-4498$

5 Isomoto H, Shikuwa S, Yamaguchi $N$ et al. Endoscopic submucosal dissection for early gastric cancer: a large-scale feasibility study. Gut 2009; 58: 331 - 336

6 Goto O, Fujishiro M, Kodashima $S$ et al. Outcomes of endoscopic submucosal dissection for early gastric cancer with special reference to validation for curability criteria. Endoscopy 2009; 41: $118-122$

7 Chung IK, Lee JH, Lee SH et al. Therapeutic outcomes in 1000 cases of endoscopic submucosal dissection for early gastric neoplasms: Korean ESD Study Group multicenter study. Gastrointest Endosc 2009; 69: $1228-1235$

8 Gotoda T, Iwasaki M, Kusano C et al. Endoscopic resection of early gastric cancer treated by guideline and expanded National Cancer Centre criteria. Br J Surg 2010; 97: 868-871

9 Ahn JY, Jung HY, Choi KD et al. Endoscopic and oncologic outcomes after endoscopic resection for early gastric cancer: 1370 cases of absolute and extended indications. Gastrointest Endosc 2011; 74: 485-493

10 Kosaka T, Endo M, Toya Y et al. Long-term outcomes of endoscopic submucosal dissection for early gastric cancer: A single-center retrospective study. Dig Endosc 2014; 26: 183-191
11 Tanabe S, Ishido K, Higuchi K et al. Long-term outcomes of endoscopic submucosal dissection for early gastric cancer: a retrospective comparison with conventional endoscopic resection in a single center. Gastric Cancer 2014; 17: 130-136

12 Oda I, Oyama T, Abe $S$ et al. Preliminary results of multicenter questionnaire study on long-term outcomes of curative endoscopic submucosal dissection for early gastric cancer. Dig Endosc 2014; 26: 214-219

13 Oyama T, Kikuchi Y. Aggressive endoscopic mucosal resection in the upper GI tract - Hook knife EMR method. Minim Invasive Ther Allied Technol 2002; 11: 291-295

14 Yamamoto H, Sekine Y, Higashizawa T et al. Successful en bloc resection of a large superficial gastric cancer by using sodium hyaluronate electrocautery incision forceps. Gastrointest Endosc 2001; 54: 629-632

15 Oda I, Gotoda T, Hamanaka $H$ et al. Endoscopic submucosal dissection for early gastric cancer: Technical feasibility, operation time and complication from a large consecutive series. Dig Endosc 2005; 17: 54-58

16 Toyonaga T, Man-I M, Fujita T et al. The performance of a novel ball-tipped flush knife for endoscopic submucosal dissection: a case-control study. Aliment Pharmacol Ther 2010; 32: 908-915

17 Nonaka S, Saito Y, Takisawa $\mathrm{H}$ et al. Safety of carbon dioxide insufflation for upper gastrointestinal tract endoscopic treatment of patients under deep sedation. Surg Endosc 2010; 24: 1638 - 1645

18 Lee WS, Cho JW, Kim KJ et al. Technical issues and new devices of ESD of early gastric cancer. World J Gastroenterol 2011; 17: 3585-3590

19 Sakurazawa N, Kato S, Fujita I et al. Supportive techniques and devices for endoscopic submucosal dissection of gastric cancer. World J Gastrointest Endosc 2012; 4: 231 -235

20 Japanese Gastric Cancer Association. Japanese classification of gastric carcinoma: 3rd English edition. Gastric Cancer 2011; 14: 101 - 112

21 Japanese gastric cancer treatment guidelines 2010 (ver. 3). Gastric Cancer 2011; 14: 113-123

22 Goto 0 , Fujishiro M, Kodashima $S$ et al. Is it possible to predict the procedural time of endoscopic submucosal dissection for early gastric cancer? J Gastroenterol Hepatol 2009; 24: 379-383

23 Ahn JY, Choi KD, Choi JY et al. Procedure time of endoscopic submucosal dissection according to the size and location of early gastric cancers: analysis of 916 dissections performed by 4 experts. Gastrointest Endosc 2011; 73: 911-916

24 Nagata S, Jin YF, Tomoeda $M$ et al. Influential factors in procedure time of endoscopic submucosal dissection for gastric cancer with fibrotic change. Dig Endosc 2011; 23: 296 - 301

25 Akasaka T, Nishida T, Tsutsui $S$ et al. Short-term outcomes of endoscopic submucosal dissection (ESD) for early gastric neoplasm: multicenter survey by Osaka university ESD study group. Dig Endosc 2011; 23: $73-77$

26 Oda I, Suzuki H, Nonaka $S$ et al. Complications of gastric endoscopic submucosal dissection. Dig Endosc 2013; 25: 71 - 78

27 Toyonaga T, Nishino E, Hirooka T et al. Intraoperative bleeding in endoscopic submucosal dissection in the stomach and strategy for prevention and treatment. Dig Endosc 2006; 18: 123 -S127

28 Suzuki H, Oda I, Sekiguchi M et al. Process of technical stabilization of gastric endoscopic submucosal dissection at the National Cancer Center in Japan. Turk J Gastroenterol 2014; 25: 619-623 